\title{
REGULAÇÃO E EXPANSÃO URBANA: A EFETIVIDADE DO ESTATUTO DA CIDADE COMO INSTRUMENTO DE CONTROLE
}

\author{
Fander de Oliveira Silva ${ }^{1}$
}

\begin{abstract}
RESUMO
Os últimos anos têm sido caracterizados por mudanças globais em favor do aumento populacional, das migrações, dos sistemas de informação, da circulação de capitais e mercadorias, dos impactos ambientais, dentre outros. Mudanças que têm sido evidenciadas principalmente nas cidades, onde são registradas mudanças na organização territorial constantemente. Este estudo de caso tem por objetivo compreender a evolução espacial da cidade, avaliando a expansão do macrozoneamento, do perímetro urbano e as características da ocupação cobrindo o intervalo correspondente aos primeiros treze anos de vigência do Estatuto da Cidade e aos oito anos de vigência do Plano Diretor do Município de Uberlândia. Os resultados demonstraram que as diversas alterações na legislação de macrozoneamento e perímetro urbano foram no sentido de atender o caráter especulativo do mercado, fomentando a indústria da valorização imobiliária privada e incitando o processo de segregação sócio espacial.
\end{abstract}

PALAVRAS-CHAVE: Expansão Urbana. Estatuto da Cidade. Plano Diretor de Uberlândia.

\section{REGULATION AND URBAN EXPANSION: THE CITY OF STATUS AS EFFECTIVE CONTROL INSTRUMENT}

\begin{abstract}
The last years have been characterized by global change in favor of population growth, migration, of information systems, denmark sales and capital, environmental impacts, among others. Changes which has been primarily evidenced in the cities, where are constantly recorded changes in territorial organization. This article aims to understand the spatial evolution of the city, evaluating the macrozoning expansion, making urban area and how occupation characteristics covering the range correspondent the first thirteen years of validity of the city Statute and to eight years of the plan do municipality of Uberlândia. The results showed as several changes in the macro-zoning of legislation and urban perimeter were not sense meet the speculative character of the market, promoting the industry of real estate valuation and private urging the segregation process socio-space.
\end{abstract}

KEYWORDS: Urban Expansion; City Statute ; Plan of Uberlândia.

${ }^{1}$ Pós-Graduando em Geografia, Universidade Federal de Uberlândia. fanderoliveira@hotmail.com. 


\title{
REGLAMENTO Y EXPANSIÓN URBANA: LA CIUDAD DE LA CALIFICACIÓN DE VIGENCIA DE CONTROL DE INSTRUMENTOS
}

\begin{abstract}
RESUMEN
En los últimos años se han caracterizado por los cambios globales en favor del crecimiento de la población, la migración, los sistemas de información, la circulación de capitales y mercancías, los impactos ambientales, entre otros. Los cambios que se han evidenciado principalmente en las ciudades donde se encuentran los cambios registrados en la organización territorial constantemente. Este artículo tiene como objetivo comprender la evolución espacial de la ciudad, la evaluación de la expansión de la macro-zonificación, los límites de la ciudad y las características de la ocupación que cubre el intervalo correspondiente a los primeros trece años del Estatuto de la Ciudad se encuentra en vigor y el término de ocho años del Plan Maestro Uberlândia. Los resultados mostraron que se han realizado los diversos cambios en la macro-zonificación y normativa perímetro urbano para responder a la naturaleza especulativa del mercado, el fomento de la industria privada de valoración de bienes raíces y fomentar el proceso de segregación socio-espacial.
\end{abstract}

PALABRAS CLAVE: La expansión urbana ; Estatuto de la Ciudad ; El Plan de Uberlândia.

\section{INTRODUÇÃO}

A análise da expansão urbana através da incorporação de novas áreas ao espaço da cidade revela-se um elemento importante para compreensão da configuração do ordenamento territorial. Tal análise oferece elementos que permitem identificar a estruturação interna, a distribuição de classes sociais e também o principal mecanismo de produção de novas áreas urbanas, que é a especulação imobiliária.

Este artigo apresenta uma análise da evolução histórico-geográfica do processo de expansão urbana do município de Uberlândia, enfocando o período 2000-2014. Objetiva-se traçar a evolução espacial da cidade, avaliando a expansão do macrozoneamento, do perímetro urbano e as características da ocupação cobrindo o intervalo correspondente aos primeiros treze anos de vigência do 


\section{Revista Nacional de}

Gerenciamento de Cidades

Estatuto da Cidade (Lei Federal no 10.257, de 10/07/2001), cuja natureza implica na ampliação de atribuições dos municípios, na exigência da participação da comunidade nas decisões públicas e normatização a lógica urbana às funções sociais da cidade e também correspondente aos oito anos de vigência do Plano Diretor do Município de Uberlândia (Lei Complementar n 432, de 19/10/2006), cujos fundamentos se amparam na garantia da função social da cidade, a prevalência do interesse coletivo sobre o individual, a proteção ao meio ambiente e a gestão integrada e compartilhada ao desenvolvimento do município.

\section{METODOLOGIA}

Quanto aos procedimentos metodológicos empregados nesta pesquisa, além da análise de uma bibliografia específica sobre o município e das legislações que amparam o planejamento urbano da cidade, efetuou-se a coleta de dados primários e secundários que foram sistematizados emmapas.

O artigo está estruturado em três seções, envolvidos na análise e compreensão da dinâmica de produção do espaço urbano de Uberlândia. $\mathrm{Na}$ primeira, apresenta-se uma discussão teórica sobre o processo de expansão urbana frente ao Estatuto da Cidade e ao Plano Diretor. Na segunda seção, examina-se a partir do Plano Diretor a incorporação dos instrumentos voltados à promoção da habitação social ao planejamento e ordenamento do espaço urbano. E por fim, em uma última seção, apresenta-se a análise da evolução deste processo de expansão urbana em Uberlândia, abordando a dinâmica do crescimento horizontal e de ocupação da terra, bem como suas implicações mais importantes do referido processo de segregação sócio espacial. 
Revista Nacional de

Gerenciamento de Cidades

\section{CARACTERIZAÇÃO DA ÁREA DE ESTUDO}

O município de Uberlândia - MG está situado na mesorregião do Triângulo Mineiro, a oeste do estado de Minas Gerais (Figura 1). Tal está localizado especificamente entre as coordenadas geográficas $18^{\circ} 30^{\prime}$ as $19^{\circ} 30^{\prime}$ de latitude sul e $47^{\circ} 50^{\prime}$ a $48^{\circ} 50^{\prime}$ de longitude oeste do meridiano de Greenwich. Seus municípios limítrofes são: Araguari, Tupaciguara, Monte Alegre de Minas, Prata, Veríssimo, Uberaba e Indianópolis. Possui uma área total de 4.115,09 km², sendo $219,00 \mathrm{~km}^{2}$ de área urbana e 3.896,09 $\mathrm{km}^{2}$ de área rural (Secretaria Municipal de Desenvolvimento Econômico e Turismo, 2013). Ainda, apresenta uma população de 604.013 mil habitantes (IBGE, 2010).

Figura 1: Localização de Uberlândia-MG.

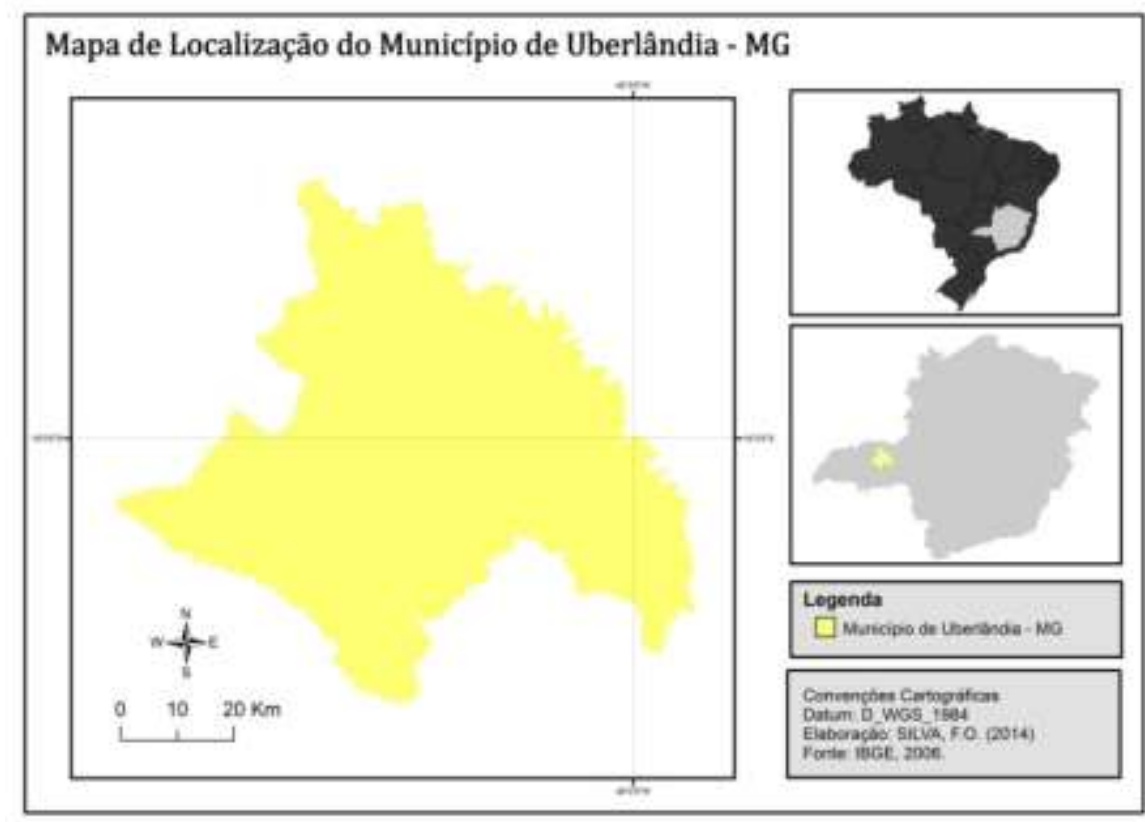

Fonte: SILVA, F.O. 2015. 
Revista Nacional de

Gerenciamento de Cidades

O município é caracterizado como importante entroncamento rodoferroviário a nível regional e nacional, fazendo com que a cidade seja um principal polo centralizador, principalmente em aspectos econômicos e comerciais.

Diante dos destaques apresentados, o planejamento se torna importante para que haja pleno desenvolvimento de todos os setores, ao propiciar o desenvolvimento e potencial da qualidade de vida, da promoção à saúde de todo o município.

\section{ESTATUTO DA CIDADE E PLANO DIRETOR: O PAPEL REGULADOR DO PODER PÚBLICO}

A partir da concretização de inúmeros processos sócio espaciais, o espaço urbano reflete as características da sociedade em um virtuoso ciclo que produz formas e conteúdos diferenciados (CASTELLS, 2000). As constantes transformações atendem à reprodução dos capitais, pelos quais indicam diferentes modelos de ocupação do espaço, que por meio dos processos sociais de uma sociedade heterogênea, é produzida uma complexa e diversificada organização espacial, onde os diferentes usos encontram se articulados pelos fluxos materiais e imateriais.

Na mediação destes processos sócio espaciais, destaca-se a atuação de forças que vão permitir as localizações, re localizações e permanências de atividades e população, forças que são culminadas, segundo Corrêa (1997), a partir dos proprietários de terra, empresas imobiliárias e de construção e o Estado, cada qual com sua estratégia.

Assim sendo, nas pesquisas sobre o espaço urbano é primordial considerar as relações sociais, que produzem as formas e estruturas do espaço geográfico de acordo com os diferentes contextos, criando novas organizações e interações espaciais. Afinal, cada tempo histórico-geográfico imprime diferentes estruturas, pelas quais devem ser consideradas para a compreensão da realidade atual. 
Revista Nacional de

Gerenciamento de Cidades

No que se refere a este processo, a expansão urbana é uma das expressões mais concretas que se realizam, na qual Côrrea (1997) destaca o papel do Estado,de forma direta, na produção do espaço urbano na realização de obras de infraestrutura, sistema viário, equipamentos e mobiliários urbanos e ainda quando constrói habitações de interesse social. E também de forma indireta, como exemplo, na regularização fundiária de favelas quando se reconhece e legitima a ocupação inicialmente irregular.

Atualmente as formas mais generalizadas de participação do Estado na produção do espaço urbano se realizam por meio da criação de normas técnicas e jurídicas de ordenação e condicionamento, entre elas podem-se citar as leis de parcelamento, zoneamento, uso e ocupação do solo urbano, as leis do sistema viário, códigos de obras e meio ambiente, entre outras. Normas estas que, destacase para muitas cidades na existência do plano diretor, que originalmente articulam todas as legislações tornando coerente e lógico o planejamento urbano que vem a disciplinar o espaço urbano da cidade.

Com a promulgação do Estatuto da Cidade (Lei Federal $n^{\circ} 10.257$, de 10/07/2001) na execução da política urbana de que tratam os artigos 182 e 183 da Constituição Federal (1988), o Plano Diretor se consolidou como instrumento técnico e jurídico, tornando-o obrigatório para as cidades com mais de 20 mil habitantes. Após este marco, uma série de legislações foram criadas para regulamentar ou complementar o texto constitucional e o Brasil teve, desde então, a questão do planejamento urbano intimamente ligado à normatização jurídica.

Conforme prevê o Art. 40 do Estatuto da Cidade o Plano Diretor deve ser elaborado com a participação da população, integrado ao processo de planejamento municipal e aprovado pelo legislativo municipal, transformando-o em lei. Em cada Plano deve se considerar, sob o ponto de vista jurídico, as diretrizes da Lei Orgânica e esta incorporada nos princípios constitucionais, regulamentando-os em escala municipal. No entanto o que ocorre na maioria dos municípios são uma reprodução mecânica dos princípios constitucionais, torando o Plano Diretor genérico e sem 
Revista Nacional de

Gerenciamento de Cidades

vinculação concomitante as demandas e potencialidades locais, na qual os interesses particulares dos proprietários de terra, das grandes empresas atuam estrategicamente estratificando cada vez mais o acesso e permanência na cidade.

Logo, esta pesquisa justifica-se na medida em que Uberlândia, como cidade média, desperta grandes interesses nas esferas político, econômicas e sociais, inerente à realidade inter e intra urbana, sob perspectivas do (re) ordenamento territorial, resultante e condicionante a uma nova fase de acumulação do capital.

\section{DINÂMICA E VALORIZAÇÃO DO ESPAÇO URBANO DE UBERLÂNDIA}

A Lei Orgânica de Uberlândia atende de forma original uma política de desenvolvimento urbano, na qual seu Art. 120 propõe a adoção dos seguintes instrumentos: código de urbanismo do município; elaboração e execução do plano diretor; leis e planos de controle do uso, parcelamento e ocupação do solo; e código de obras e edificações.

Nesta premissa o município criou, em 4 de Outubro de 1988, a Lei $n^{\circ} 4.790$ que estabelecia o perímetro urbano da sede doMunicípio de Uberlândia, na qual foi substituída posteriormente pela Lei $n^{\circ} 5.969$ de 7 de março de 1994 e assim sucessivamente ( Lei $n^{\circ} 10.575$ de Setembro de 2010, Lei $n^{\circ} 11.412$ de 19 de Junhode 2013, Lei no 11.819 de 9 de Junho de 2014).

Quanto à normatização do zoneamento e parcelamento de uso e ocupação do solo urbano, a primeira Lei estabelecida foi a de $n^{\circ} 224$, publicada em 23 de Dezembro de 1999, a qual ordenou critérios do zoneamento de uso e ocupação do solo urbano, definindo as áreas de composição a Zona Urbana, a Zona de Expansão Urbana; a Zona Rural e a Zona de Urbanização Específica. A partir da sua criação esta lei foi alterada várias vezes com objetivo de reorientar e adequar as classificações de uso a interesses diversos pelas: (Lei Complementar $n^{\circ} 245$ de 30 de novembro de 2000, Lei Complementar $n^{\circ} 383$ de 26 de outubro de 2004, Lei Complementar $n^{\circ} 52$ de 7 de abril de 2011, Lei Complementar $n^{\circ} 525$ de 14 de abril 


\section{Revista Nacional de}

Gerenciamento de Cidades

de 2011, Lei Complementar $n^{\circ} 565$ de 19 de junho de 2013). Várias ementas à lei foram aprovadas com o intuito de regularizar $\mathrm{o}$ atendimento às necessidades de expansão da cidade.

Diferente da maioria destas cidades, Uberlândia participa efetivamente do processo de adequação ao Estatuto das Cidades e teve em 2006 a revisão do seu Plano Diretor. Suas revisões remeteram a questões alusivas ao zoneamento do território urbano, ampliando a composição do perímetro e a expansão urbana. Este Plano Diretor foi criado pela Lei Complementar $n^{\circ} 432$, de 19 de outubro de 2006, e foi reconhecido, no art. $2^{\circ}$ como o:

[...] principal instrumento da política de desenvolvimento urbano e ambiental de Uberlândia, tendo por objetivo orientar a atuação do Poder Público e da iniciativa privada, bem como atender às aspirações da comunidade, constituindo-se na principal referência normativa das relações entre o cidadão, as instituições e o meio físico.

Para o ordenamento territorial, o Plano Diretor de 2006 trouxe o conceito de Macrozoneamento, considerando a inter-relação entre os fatores naturais e a antrópicos (Art. 21, I) e zoneamento urbano, "que define e delimita as zonas urbanas, de acordo com o grau de urbanização e o seu padrão de uso e ocupação desejável" (Art. 21, II). O macrozoneamento definido no Plano Diretor estabelece dois âmbitos territoriais distintos: o macrozoneamento geral, que cobre toda a extensão do território do município e um macrozoneamento do distrito sede, conforme a Figura 2, a seguir. 


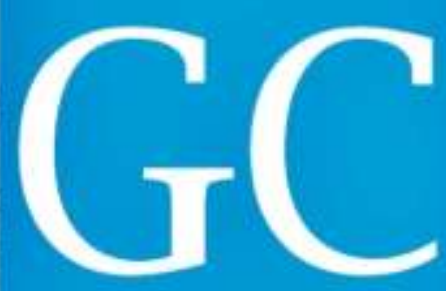

Revista Nacional de

Gerenciamento de Cidades

Figura 2: Macrozoneamento e Perímetro Urbano de Uberlândia, Plano Diretor 2006.

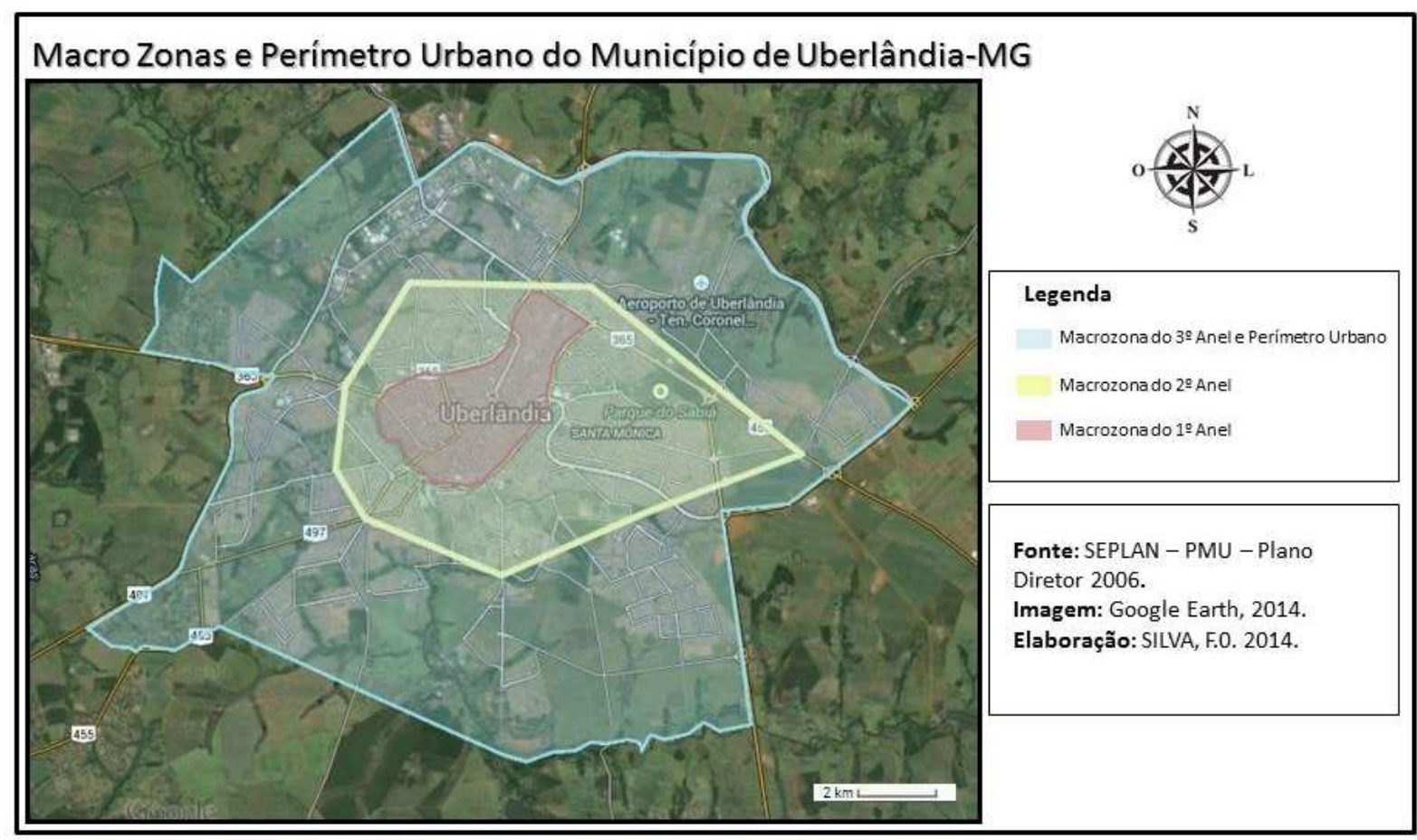

Fonte: SILVA, F.O. 2015.

Para o macrozoneamento geral foram definidas em três anéis: (1) Macro Zona do $1^{\circ}$ Anel: compreende as área da região já consolidada e mais adensada, com infraestrutura otimizada, onde está localizado o terminal central de transporte coletivo; (2) Macro Zona do $2^{\circ}$ Anel: compreende a região entre o primeiro e o segundo anel viário. Nesta região pretende-se a consolidação dos sub centros; (3) Macro Zona do $3^{\circ}$ anel: compreende a região entre o segundo e o terceiro anel, que coincide com a delimitação do perímetro urbano. É a região onde estão concentrados os bairros periféricos, áreas não ocupadas, grandes indústrias e serviços. Para esta macro zona está previsto os núcleos de vizinhança e zonas especiais de interesse social - ZEIS.

Em 26 de Março de 2010 é lançado o Decreto n 12.158, que cria oito novas Zonas de Especiais de Interesse Social - ZEIS, para a implementação do Programa Federal De Habitação "Minha Casa, Minha Vida", no qual se destaca regiões conhecidas hoje como Shopping Park, Jardim Glória, Jardim Sucupira. 


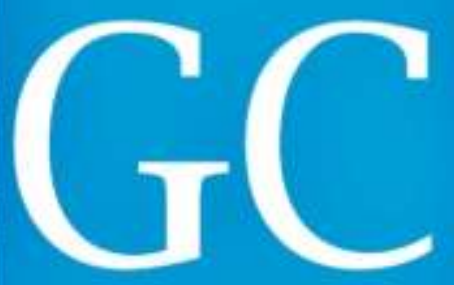

Revista Nacional de Gerenciamento de Cidades

Em 2011 a nova Lei de Zoneamento, Uso e Ocupação do Solo (Lei Complementar $n^{\circ} 525$ de 14 de Abril de 2011)revogou a legislação de 2000 e suas emendas. Tais mudanças visavam, dentre outros fatores, otimizar os deslocamentos urbano, regulamentar a implantação de condomínios fechados, estratificar as zonas residenciais e formalizar as zonas especiais de interesse social.E recentemente, a Lei $n^{\circ} 11.819$ de 9 de Junho de 2014, faz saber o perímetro urbano atual da sede do município de Uberlândia, conforme a Figura 3 apresenta:

Figura 3: Perímetro Urbano de Uberlândia, Lei Complementar $n^{\circ} 11.819$.

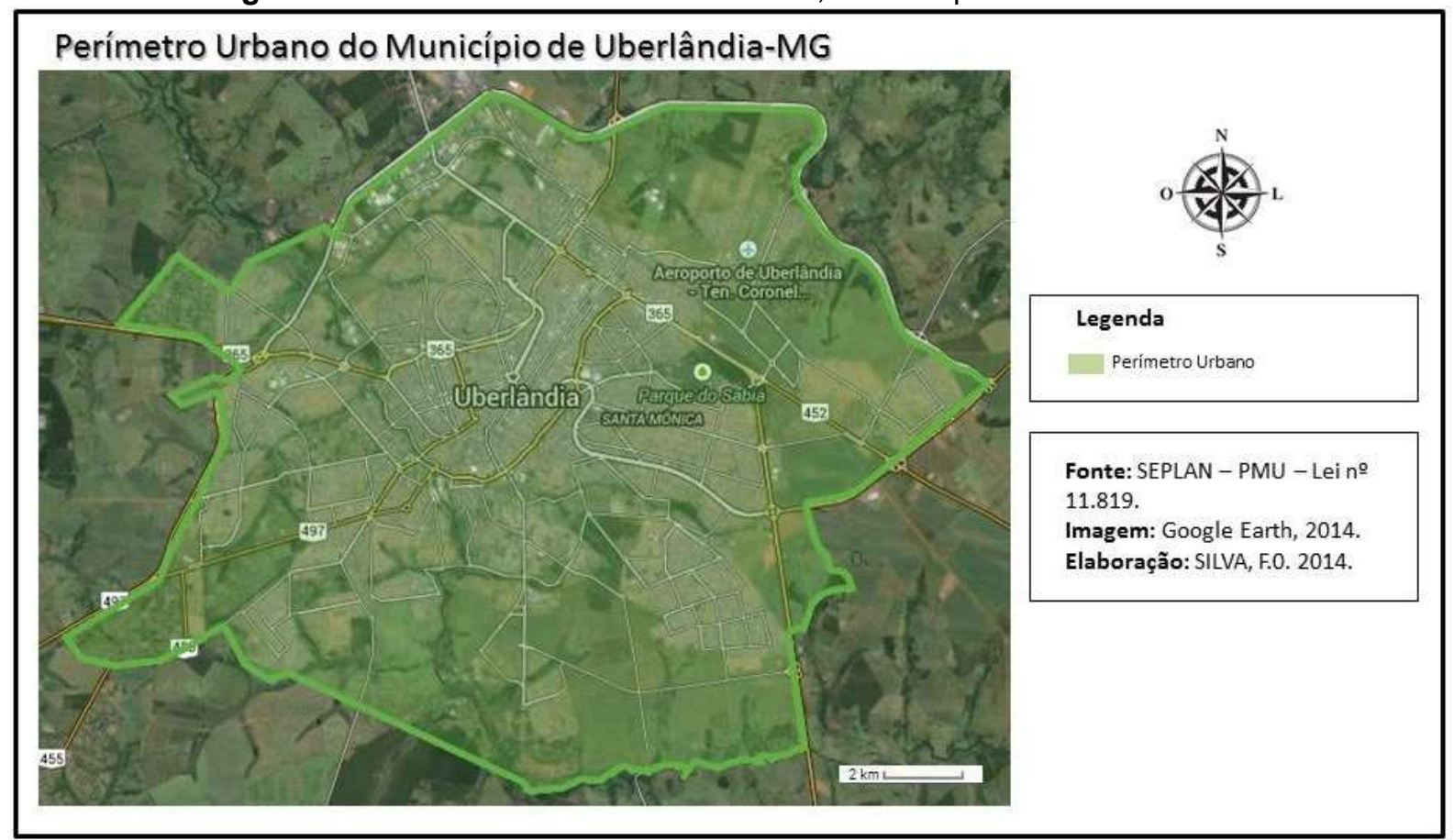

Fonte: SILVA, F.O. 2015.

Compreende-se que as diversas alterações na legislação de zoneamento e parcelamento de uso e ocupação do solo urbano, de expansão do perímetro urbano de Uberlândia nos últimos dez anos, foram ao sentido de atender o caráter especulativo do mercado, fomentando a indústria da valorização imobiliária, estimulando a ocupação de espaços urbanos que tendam a segregação sócio espacial e a privatização de espaços públicos. 


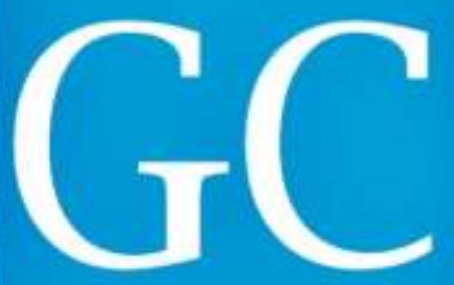

Revista Nacional de

Ao longo desta última década, a política urbana de Uberlândia ficou centralizada nas mãos do poder público em função da classe dominante, pela qual se evidenciou em uma dinâmica espacial que sucedeu privilégios a alguns setores considerados fundamentais na relação político-econômica. Tal que a abertura dos loteamentos, principalmente para atender o Programa Federal de Habitação "Minha Casa, Minha Vida" deixou para trás imensos vazios urbanos à espera da valorização imobiliária, resultando em uma exorbitante segregação sócio espacial (falta de acesso aos equipamentos e serviços urbanos, condições insalubres, falta de postos de trabalho, serviço, lazer, saúde e segurança, dentre outros) conforme aponta a figura a seguir:

Figura 4: Vazios Urbanos de Uberlândia.
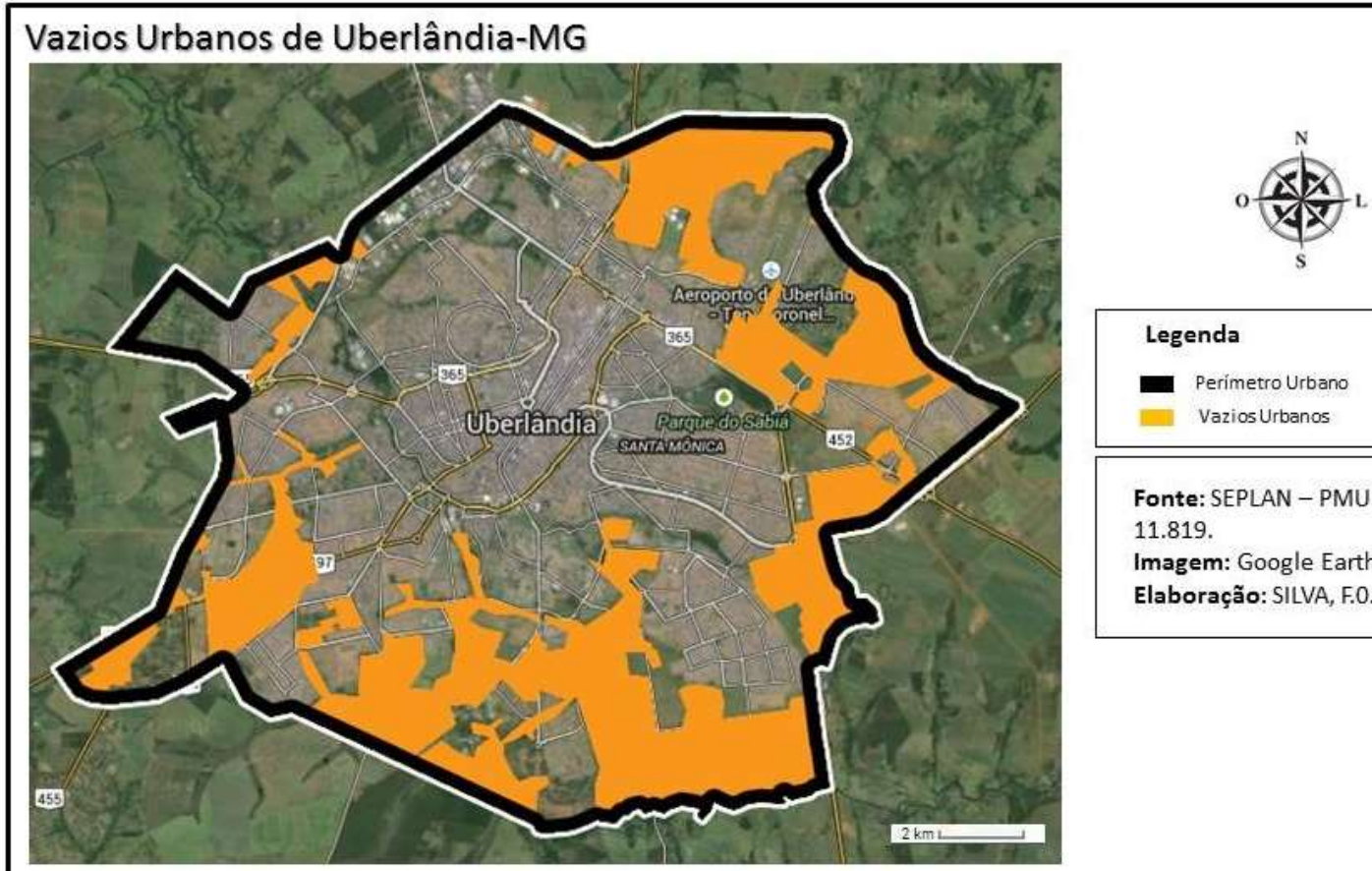

Fonte: SILVA, F.O. 2015 


\section{CONSIDERAÇÕES FINAIS}

A cidade de Uberlândia se produz e reproduz à luz da reprodução do capital, visando à apropriação dos recursos disponíveis e indisponíveis oferecidas pelo Estado Brasileiro, sem preocupações com os inúmeros problemas que vem a ser acarretados.

Com este trabalho foi possível identificar a existência de inúmeras legislações que permearam as diferentes espacialidades e temporalidades na apropriação do espaço urbano da cidade, e que embora as mesmas representem um grande avanço ao ordenamento da cidade, devido à descrição dos limites do município, o perímetro, ao macrozoneamento municipal, a cidade de Uberlândia, assim como tantas outras cidades brasileiras não tem garantido o que o Estatuto da Cidade assegura (o direito a cidades sustentáveis, à terra urbana, a moradia, ao saneamento ambiental, a infraestrutura urbana, ao transporte e aos serviços públicos, ao trabalho e lazer).

Para o novo Plano Diretor, que deve ser revisto em 2016, espera-se que os planos e projetos envolvam a reabilitação de um perímetro urbano, pelo qual se faça o levantamento da situação socioeconômica dos últimos loteamentos abertos, dos potenciais das macro zonas e dos vazios urbanos (imóveis subutilizados, dos depósitos e edifícios industriais-comerciais) a fim de readequar e utilizar estes espaços para atender a inclusão social e efetivamente promover o conceito de cidade compacta.

\section{REFERÊNCIAS}

BRASIL. Constituição (1988). Constituição [da] Republica Federativa do Brasil. Brasília, DF: Senado Federal, 1988.

CASTELLS, M. A questão urbana. Rio de Janeiro: Paz e Terra, 2000.

CORREA, L. Trajetórias Geográficas. Rio de Janeiro: Bertrand Brasil, 1997. 
BRASIL. Estatuto da Cidade: Lei 10.257/2001 que estabelece diretrizes gerais da política urbana. Brasília, Câmara dos Deputados, 2001, 1ª Edição.

PREFEITURA MUNICIPAL DE UBERLÂNDIA (PMU). Decreto n $^{\circ} \mathbf{1 2 . 1 5 8}$ de 26 de Março de 2010. Uberlândia: PMU/Câmara Municipal dos Vereadores, 2010.

Lei Complementar no 245 de 30 de novembro de 2000.Uberlândia: PMU/Câmara $\overline{\text { Municipal }}$ dos Vereadores, 2000.

Lei Complementar $n^{\circ} 383$ de 26 de outubro de 2004. Uberlândia: PMU/Câmara $\overline{\text { Municipal }}$ dos Vereadores, 2004. Vereadores, 2011.

Lei Complementar $\mathbf{n}^{\circ} 52$ de 7 de abril de 2011. Uberlândia: PMU/Câmara Municipal dos

Lei Complementar $n^{\circ} 525$ de 14 de abril de 2011. Uberlândia: PMU/Câmara Municipal dos Vereadores, 2011.

Lei Complementar $n^{\circ} 565$ de 19 de junho de 2013. Uberlândia: PMU/Câmara Municipal dos Vereadores, 2011.

Lei $n^{\circ} 224$ de 23 de Dezembro de 1999 . Uberlândia: PMU/Câmara Municipal dos Vereadores, 1999.

Vereadores, 2010.

Lei $n^{\circ} 10.575$ de 20 Setembro de 2010. Uberlândia: PMU/Câmara Municipal dos Vereadores, 2013.

Lei $n^{\circ} 11.412$ de 19 de Junho de 2013. Uberlândia: PMU/Câmara Municipal dos

Lei $n^{\circ} 11.819$ de 9 de Junho de 2014. Uberlândia: PMU/Câmara Municipal dos Vereadores, 2014.

Lei Orgânica do Município de Uberlândia. Uberlândia: PMU/Câmara Municipal dos Vereadores, 1990.

Plano Diretor Lei Complementar n 432 de 19 de outubro de 2006. Uberlândia: PMU, 